\title{
Archéopages
}

Archéopages

Archéologie et société

\section{Territoires languedociens de la Protohistoire au Moyen âge. Nouvelles données sur les campagnes de Nîmes, Lodève et Béziers}

Hervé Pomarèdes, Florent Mazière, Pierre Séjalon, Valérie Bel, Jean-Yves Breuil, Olivier Ginouvez, Cécile Jung et Odile Maufras

\section{OpenEdition}

Journals

Édition électronique

URL : https://journals.openedition.org/archeopages/378

DOI : $10.4000 /$ archeopages.378

ISSN : 2269-9872

Éditeur

INRAP - Institut national de recherches archéologiques préventives

Édition imprimée

Date de publication : 1 février 2012

Pagination : 10-21

ISSN : 1622-8545

Référence électronique

Hervé Pomarèdes, Florent Mazière, Pierre Séjalon, Valérie Bel, Jean-Yves Breuil, Olivier Ginouvez, Cécile Jung et Odile Maufras, « Territoires languedociens de la Protohistoire au Moyen âge. Nouvelles données sur les campagnes de Nîmes, Lodève et Béziers ", Archéopages [En ligne], 34 | 07/2012, mis en ligne le 01 juillet 2012, consulté le 21 janvier 2022. URL : http://journals.openedition.org/ archeopages/378; DOI : https://doi.org/10.4000/archeopages.378 


\title{
Territoires languedociens
}

\section{de la Protohistoire au Moyen âge. Nouvelles données sur les campagnes de Nîmes, Lodève et Béziers}

\author{
H. Pomarèdes Irrap, UMR S140 «Archeologie des societets medititrraneennes" \\ F. Mazière Irrap, UMR 5608 «TRACES, \\ P. Séjalon, V. Bel, J.-Y. Breuil, O. Ginouvez, C. Jung, O. Maufras Inrap, UMR S140 «Archeologie des societéts méditerranéennes"
}

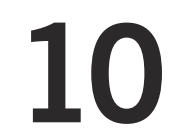

1. Par l'Inrap, en étroite collaboration avec le SRA du Languedoc-Roussillon, 2. PCR Nîmois « Espace rural et occupation du sol de la région nîmoise, de la Préhistoire à l'époque moderne» (resp. : J.-Y. Breuil, Inrap), ARC Inrap « Paysages et organisation socio-économique des campagnes du Lodévois et du Biterrois (Languedoc central) de la protohistoire au Moyen âge » (resp. : H. Pomarèdes, C. Jung, Inrap).
Ces deux dernières décennies, l'archéologie préventive menée $\mathbf{1}^{\mathbf{1}}$ dans les territoires de Nîmes, Lodève et Béziers a investi près d'un millier d'hectares. Cette riche documentation, dont l'exploitation est en cours', permet de livrer un bilan liminaire ayant trait à l'histoire du monde rural. Dans l'article qui suit, nous avons privilégié la dimension diachronique, démarche qui révèle la persistance des héritages mais aussi les changements, notamment ceux liés aux divers stimuli d'origine méditerranéenne. L'exposé porte sur deux régions ; la première englobe l'ouest du département de l'Hérault, où les vallées de l'Orb et de l'Hérault relient la Méditerranée aux Causses [ill.1] ; la seconde concerne, dans le Gard, la région de Nîmes et la plaine du Vistre qui s'étend des lagunes aux premiers reliefs (les Garrigues), jusqu’à la vallée du Rhône. On essaiera de mettre en évidence leur organisation territoriale, économique et sociale en insistant plus particulièrement sur trois aspects, l'évolution sur la longue durée des formes de l'habitat rural, les relations entre ces derniers et les grandes agglomérations et enfin, les modes de productions agricoles à travers l'exemple emblématique de la viticulture.

\section{Lodévois et Biterrois}

Les modes d'organisation du peuplement protohistorique en Languedoc central

L'archéologie protohistorique du Languedoc central fut longtemps cantonnée aux seuls oppida. Fondés majoritairement dans le courant de la première moitié $\mathrm{du} \mathrm{VI}^{\mathrm{e}} \mathrm{s}$. av. notre ère, ces agglomérations de hauteur souvent fortifiées, s'étendent sur une dizaine d'hectares. Leur schéma urbanistique prononcé trahit l'attrait des sociétés de l'âge du Fer pour un modèle de développement résolument urbain. Les oppida de Pech-Maho, du Cayla, de Montlaurès, d'Ensérune ou de Béziers correspondent tout à la fois à des lieux de productions et d'échange, à des centres de pouvoir et sont assimilés à des capitales régionales. Dans les années 1960-70, de rares chercheurs se sont intéressés aux habitats ruraux. Ce n'est qu’à partir des années 1990, grâce à l'archéologie préventive, que l'on a pu souligner la diversité de ces derniers.

Le champ de ces découvertes est encore largement ouvert du fait de la rareté des grands décapages, mais un premier bilan est déjà possible, il se diviserait en trois étapes [ill.2]. On perçoit tout d'abord un accroissement du nombre des occupations au milieu du Bronze final à l'image de l'habitat du Bronze final I/II du Petit Garlambaut (Béziers). La deuxième étape débute à l'extrême fin de cette période, entre le $\mathrm{X}^{\mathrm{e}}$ et le $\mathrm{IX}^{\mathrm{e}} \mathrm{s}$. av. notre ère. Les nécropoles à incinération regroupent des centaines de sépultures (La Rouquette, Puisserguier) et sont parfois utilisées jusqu'à la fin du VII ${ }^{\mathrm{e}} \mathrm{s}$. av. notre ère. Elles sont liées à des habitats répartis dans un rayon de 300 à $1000 \mathrm{~m}$. Certains d'entre eux sont pourvus de fortifications (Portal-Vielh, Vendres), d'autres sont d'apparence plus modestes. Au cours des VIII ${ }^{\mathrm{e}}$ et $\mathrm{VII}^{\mathrm{e}} \mathrm{s}$. av. notre ère, on assiste au développement d'habitats lâches qui s'étendent sur de vastes étendues (La Galiberte, Vendres). Ce type d'occupation disparait au cours de la première moitié $\mathrm{du} \mathrm{VI}^{\mathrm{e}} \mathrm{s}$. av. notre ère, parallèlement au développement des échanges et à l'installation de comptoirs grecs dans la basse vallée de l'Hérault, à La Monédière (Bessan) et à Agde (Agáthe ou Agathé Tyche). Dans cette vallée, aux abords de l'oppidum de Saint-Siméon (Pézenas), nos recherches montrent le regroupement des populations sur cette hauteur. Et ce phénomène se reproduit en divers endroits de la région (Mazière et al., 2012).

La dernière étape débute donc entre la fin 


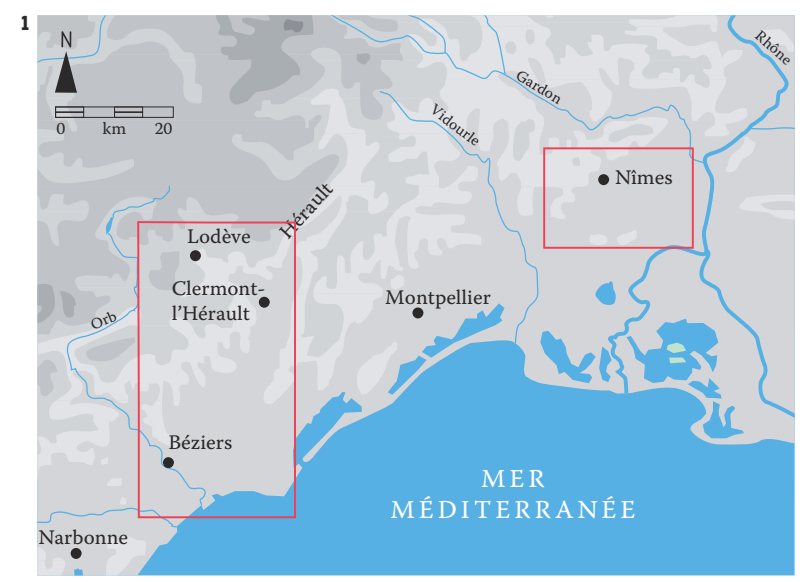

calisation des zones d'étude de l'ARC LodévoisBiterrois et du PCR Nîmois. 2. Schéma synthétique des caractéristiques de l'espace rural entre le début du Bronze final et le milieu du second âge du Fer. Sont représentés es principaux éléments qui structurent l'espace, les types d'habitat et des croquis restituant les dynamiques d'occupation à l'échelle d'un terroir. A. Le petit Garlambaut (Béziers, Hérault).Sur une superficie de $2700 \mathrm{~m}^{2}$ 32 structures se rapportant au Bronze final I/Ila et III ont été découvertes.

Elles occupent $560 \mathrm{~m}^{2}$.

Un paléo-chenal a été

recreusé par un fossé comblé au Bronze final I/

Ila (fouille Inrap,

B. Sendra et F. Mazière)

B. Les Garennes (Tourbes,

Hérault). Le site

correspond à une aire

d'ensilage qui se compose

de 8 silos répartis sur

une superficie décapée

de $1500 \mathrm{~m}^{2}$. Ils sont tous

datés à la charnière des

vII et vie siècles av.J.-C.

Le site a pu être mis en

relation avec un autre

gisement du même type,

localisé à proximité
(Fouille Inrap., B. Sendra

et F. Mazière).

C. Les Cresses Basses

(Montblanc, Hérault).

Le site, très arasé par les

labours, a livré seulement

deux fosses auxquelles

s'ajoutent deux

concentrations de

mobiliers, soit une

superficie de $3000 \mathrm{~m}^{2}$

environ. Il est daté entre

la fin du vie et le premier

quart du ve s. av. J.-C.

II correspondrait à un

établissement agricole

sans lien direct avec

un oppidum (Fouille Inrap,

C.Jung).
TENDANCES GÉNÉRALES

2

IV

abandon des établissements ruraux

$\mathrm{V}^{\mathrm{e}}$

$\mathrm{VI}^{\mathrm{e}}$

$\mathrm{VII}^{\mathrm{e}}$

VIII

$\mathrm{IX}^{\mathrm{e}}$

$\mathrm{X}^{\mathrm{e}}$

$\mathrm{XII}^{\mathrm{e}}$

$\mathrm{XIII}^{\mathrm{e}}$

$\mathrm{XIV}^{\mathrm{e}}$ petits établissements ruraux

regroupement de l'habitat et fondation des oppida

habitat à organisation lâche

petits habitats dispersés habitats fortifiés

apparition des grandes nécropoles à incinération

petits habitats dispersés habitats fortifiés

croissance du nombre d'habitats sites funéraires inconnus
DÉCOUVERTES RÉCENTES
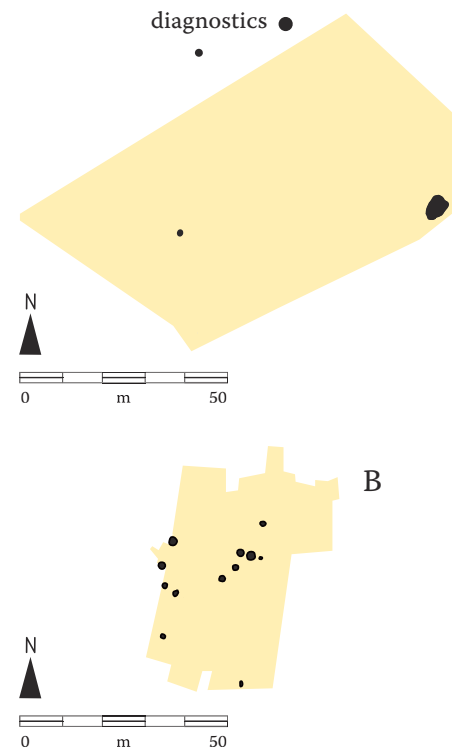

C

étape 1

shéma d'occupation inconnu

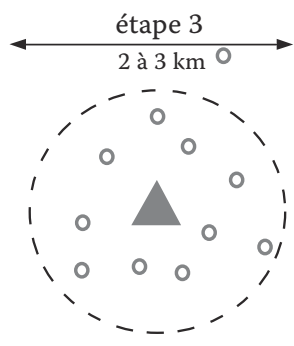

Établissements ruraux $\triangle$ Oppidum

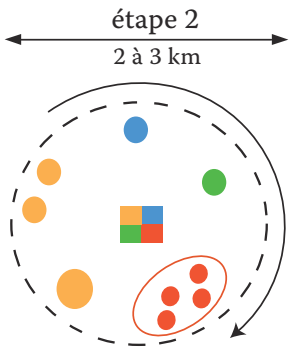

Habitat

Nécropole

$\mathrm{X}^{\mathrm{e}} / \mathrm{IX}^{\mathrm{e}}$

$\mathrm{IX}^{\mathrm{e}} / \mathrm{VIII}^{\mathrm{e}}$

$\mathrm{VIII}^{\mathrm{e}} / \mathrm{VII}^{\mathrm{e}}$

Fin $\mathrm{VII}^{\mathrm{e}} /$ début $\mathrm{VI}^{\mathrm{e}}$

A

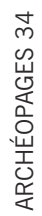




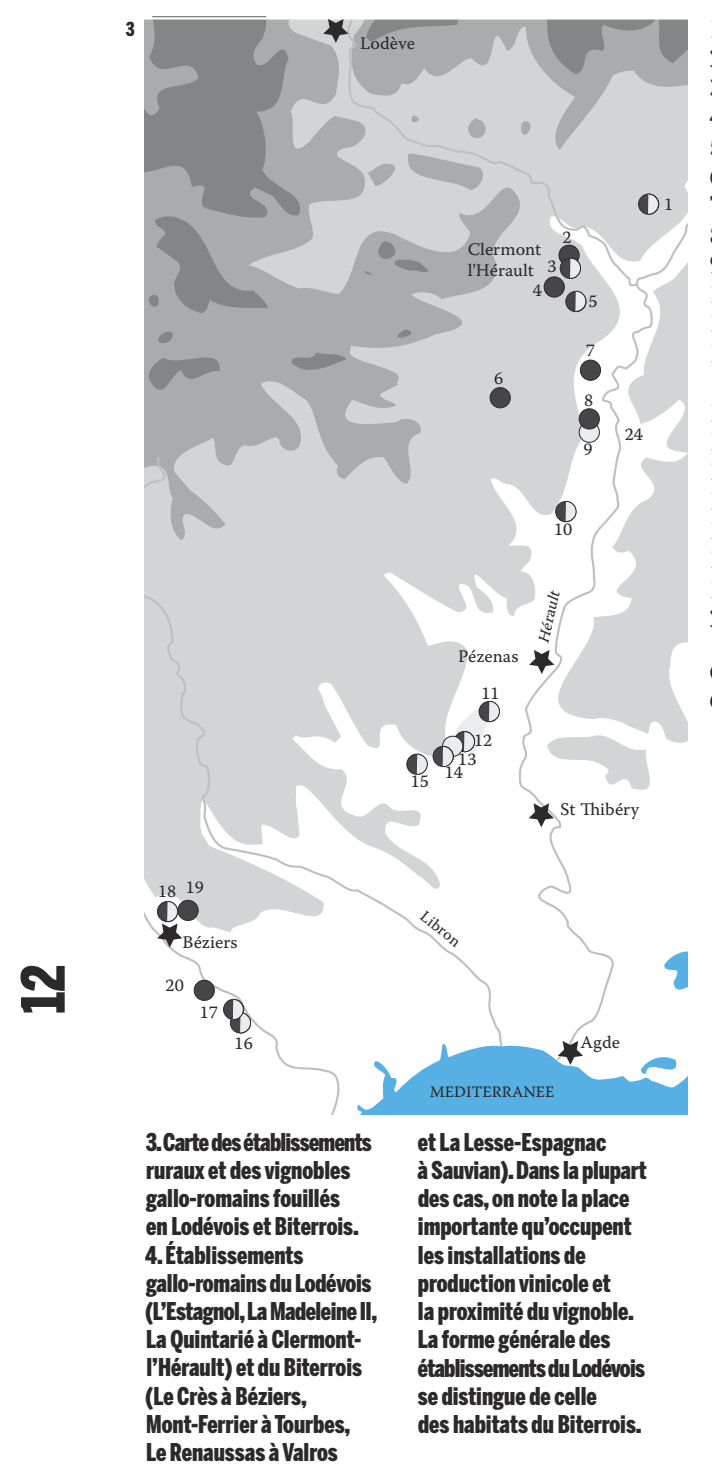

4

2: L'Estagnol

3 : Peyre Plantade

4 : La Madeleine II

5: La Quintarié

6: Combes de Fignols

7 : Saint-Bézard

8 : Soumaltre, Soumaltre sud

9: Mas de Pascal

10 : Vareilles

11 : Mont Ferrier

12 : Rec de Ligno, Labournas,

Vigne de Bioaux (Aire de Repos)

13 : Champ Redon

$14:$ Renaussas

15 : Cresses Basses

16 : La Lesse-Espagnac

17 : La Domergue

18 : Gasquinoy

19 : Le Crès

20 : Notre Dame de Consolation

- établissement vinicole

O champs de vignes et/ou vergers

Altitudes (m)

400

200

50
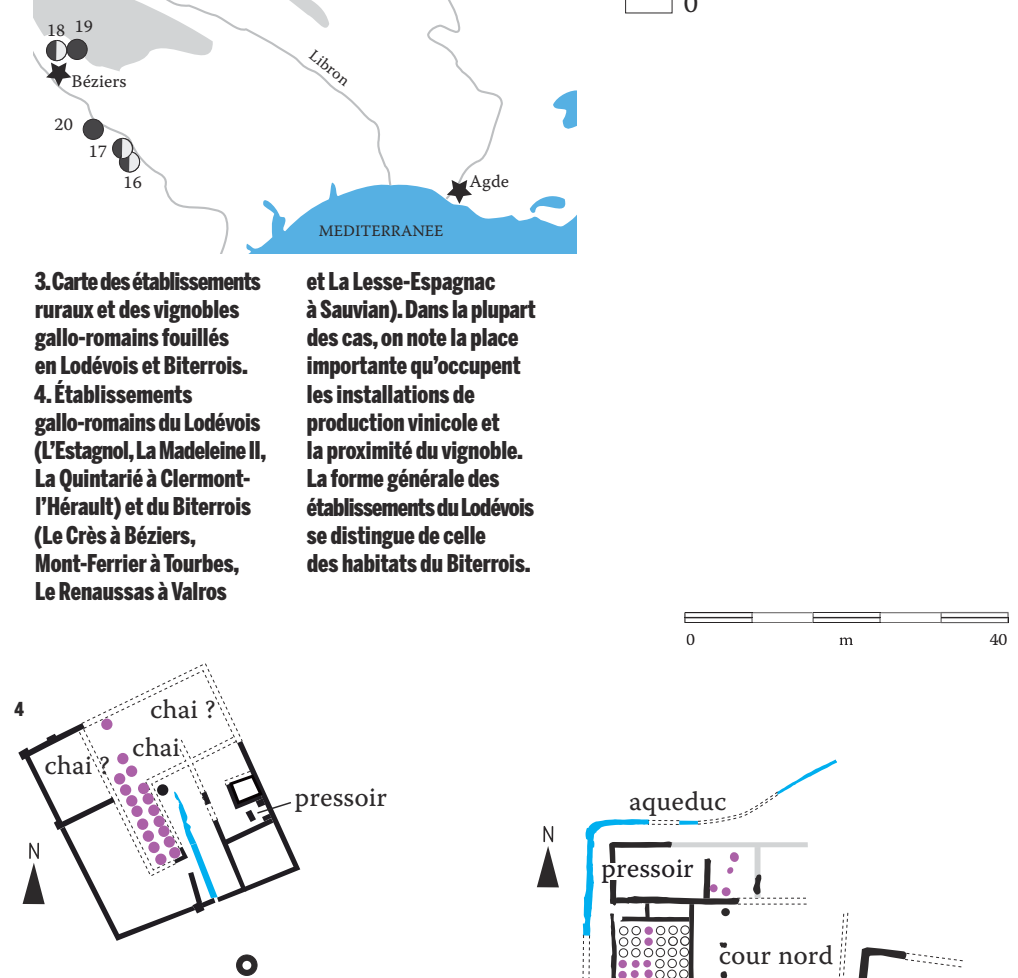

Le Renaussas (Valros, 34)

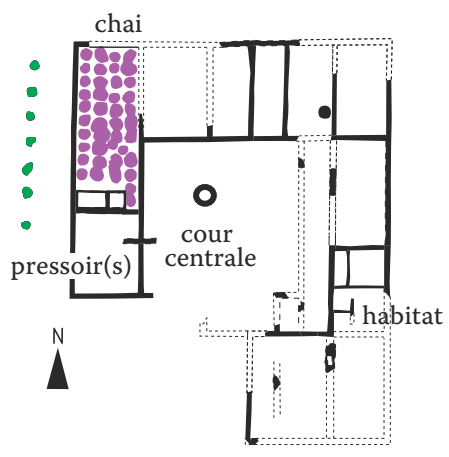

Le Crès (Béziers, 34)

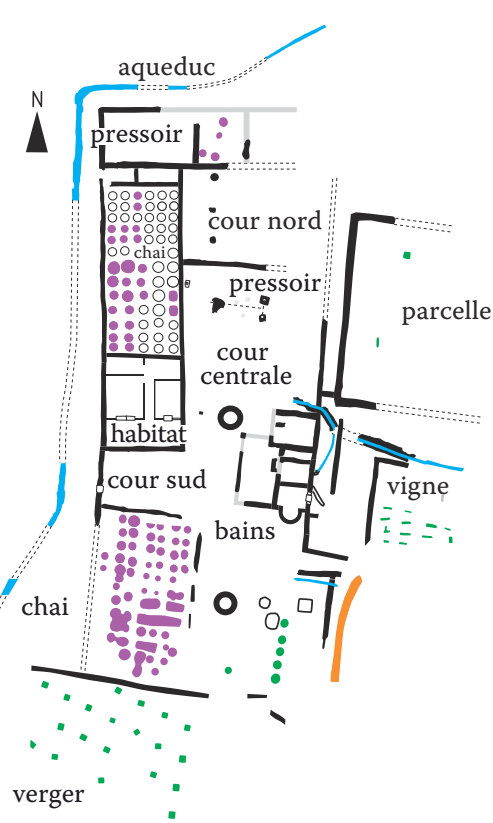

La Lesse-Espagnac (Sauvian, 34)

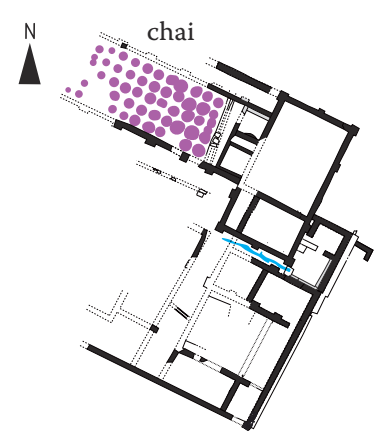

Mont Ferrier, état 4 (Tourbes, 34)

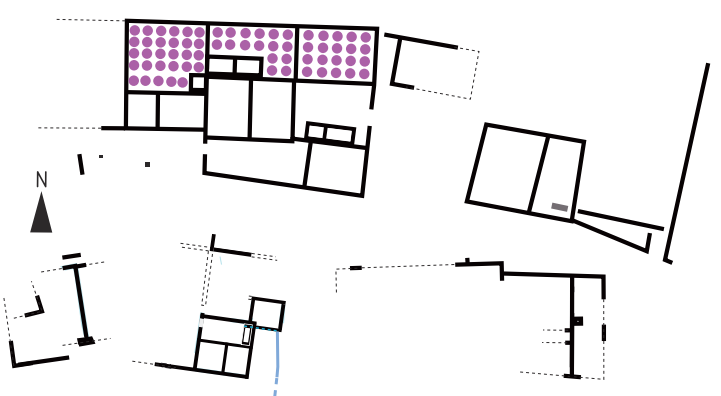

L'Estagnol (Clermont-l'Hérault, 34)

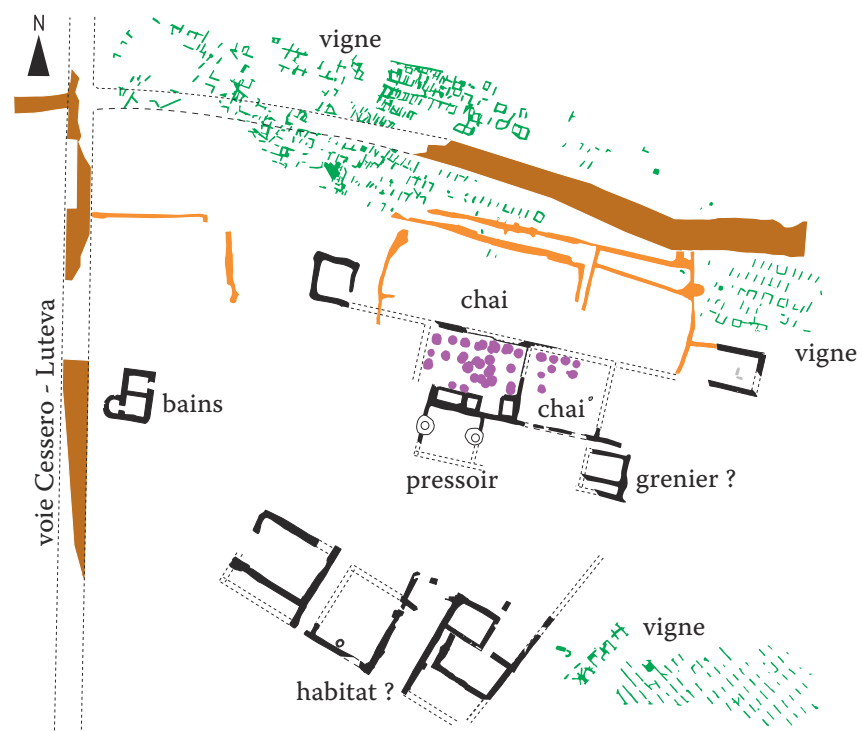

La Quintarié (Clermont-l’Hérault, 34)

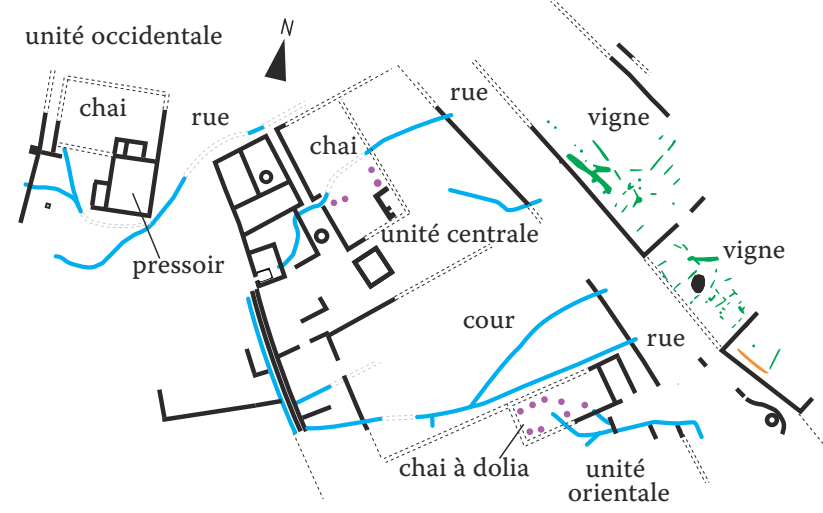

La Madeleine II (Clermont-l’Hérault, 34) 
$d u \mathrm{VI}^{\mathrm{e}} \mathrm{s}$. et la fin du IV ${ }^{\mathrm{e}} \mathrm{s}$. av. notre ère, quand de nouveaux établissements ruraux de petite taille se déploient, cette fois-ci en périphérie de ces grands habitats. Ils mettent en valeur des espaces vivriers placés sans doute sous le contrôle direct des oppida. Une telle organisation apparaît assez nettement en périphérie de Béziers où l'on compte pas moins de vingt-et-une implantations dans un rayon de 2 à $3 \mathrm{~km}$ (établissements ruraux, atelier de potier, vestiges épars). Cette forme d'occupation n'apparaît pas exclusive. La présence de sépultures à caractère élitaire, d'habitats ruraux et d'ateliers de potiers (Mas de Pascal à Aspiran), installés dans la profondeur des campagnes témoignerait d'une organisation foncière plus complexe et hiérarchisée. Le fonctionnement de ces nouveaux réseaux échappe cependant à l'analyse faute d'une documentation adéquate. Pour l'heure, notons seulement que les études des mobiliers démontrent des échanges de faible ampleur. Ce cycle s'achève dans le courant $\mathrm{du} \mathrm{III}^{\mathrm{e}} \mathrm{s}$. av. notre ère, quand le nombre de sites diminue. Cette tendance pose de nouvelles questions. Elle s'apparenterait à une crise touchant à la fois agglomérations et campagnes.

\section{Les territoires de Clermont-l'Hérault et de la vallée de l'Hérault aux confins des cités antiques de Nîmes, Lodève et Béziers}

Aux cours des $\mathrm{II}^{\mathrm{e}}$ et $\mathrm{I}^{\mathrm{er}} \mathrm{S}$. av. notre ère, l'habitat rural s'épanouit à nouveau en Biterrois, dans la vallée de l'Hérault comme sur le littoral agathois. Ces situations sont analysées depuis plusieurs décennies grâce à d'importantes campagnes de prospections, des approches quantitatives et des regards croisés entre historiens, archéologues et géographes. Malgré les investigations menées sur le Gazoduc « Artère du Midi » ou sur l'autoroute A75 (Peyre Plantade à Clermont-l'Hérault, Mas de Pascal à Aspiran ou encore Vareilles à Paulhan) [ill.3], l'habitat de ces périodes précoloniale et républicaine reste fort mal connu; plus encore que dans la région de Nîmes et dans la vallée de l'Aude où l'on perçoit plus clairement leur organisation dans de grands enclos fossoyés.

Qu'il s'agisse de simples annexes agraires, de modestes fermes, d'habitats précurseurs du système domanial ou représentatifs des assignations de terres, leur nombre augmente tout au long de cette période. Leur diffusion s'opère encore après le milieu du $\mathrm{I}^{\mathrm{er}} \mathrm{s}$. av. notre ère, parallèlement à la fondation des colonies de Béziers et de Nîmes dont la frontière commune se situerait en rive gauche de l'Hérault. L'accession de plusieurs agglomérations de la vallée (Cessero/Saint-Thibéry, Piscinael Pézenas? et Luteva/Lodève) au statut d'oppidum latinum, met en lumière, elle aussi, l'importance de cette région. L'objectif de Rome serait ici d'exploiter, grâce à sa protection, l'une des principales pénétrantes vers le Massif Central et les territoires Rutène et Gabale à des fins stratégiques et commerciales. Ce dispositif se développe durablement dans le bassin de Clermont-l'Hérault, aux confins des territoires de Nîmes et Béziers mais aussi de Lodève qui accède, au début du $\mathrm{I}^{\mathrm{er}} \mathrm{s}$. ap. notre ère, au statut de colonie. La nouvelle cité assure alors le contrôle des ressources forestières et minières des contreforts du Larzac et développe son agriculture, non pas à sa périphérie où les terres fertiles sont rares, mais à près de $20 \mathrm{~km}$ de là, dans les finages moins escarpés de la vallée de l'Hérault. Cette organisation singulière permet le développement de la viticulture dans la colonie comme dans celle de Béziers. Les découvertes récentes de l'Inrap dans les agglomérations agricoles de La Madeleine, de Peyre Plantade, dans les exploitations de L'Estagnol et de La Quintarié (Clermont-l'Hérault) [ill.4] permettent également de mettre en lumière des systèmes agraires distincts de celui de la villa, modèle plus répandu sur le littoral. Les situations de la seconde moitié du $\mathrm{I}^{\mathrm{er}} \mathrm{s}$. se prolongent durant tout le $\mathrm{II}^{\mathrm{e}} \mathrm{s}$. Les voies de communication sont entretenues et fixent à leurs abords des ateliers de potiers (Soumaltre et Soumaltre Sud à Aspiran), des balnéaires d'étape (Soumaltre Sud, La Quintarié) (Pomarèdes dir., 2005) ou encore une auberge (Soumaltre Sud). L'agglomération de Peyre Plantade, implantée au pied de l'ancien oppidum de La Ramasse, ferait durablement office de lieu de rupture de charge et de place commerciale. Un relais routier y est installé ainsi qu'un forum et des thermes dont l'architecture soignée rompt avec celle de l'habitat vernaculaire contemporain. Implantés aux carrefours ou le long des chemins qui irriguent la campagne, les ensembles funéraires témoignent quant à eux, par leur diversité, des différentes composantes de la société rurale. L'analyse croisée de l'organisation des espaces, des pratiques funéraires, des mobiliers et des données anthropologiques, permet ainsi de reconnaître, à Valros, un ensemble dévolu aux travailleurs serviles d'un domaine (La Vigne de Bioaux) et un mausolée associé à un sanctuaire domanial (Rec de Ligno) (Jung, Bel dir., 2010 ; Bel, Gleize, à paraître).

\section{Les productions et les systèmes agraires gallo-romains}

L'économie céréalière de la région commence à être perçue grâce à la découverte de greniers et de moulins hydrauliques (Mauné et al., 2007). Les vestiges ayant trait aux activités vinicoles sont bien plus abondants et illustrent des pratiques très variées. En Clermontais, à partir de la fin du $\mathrm{I}^{\mathrm{er}} \mathrm{s}$. av. notre ère et jusquà la fin du $\mathrm{II}^{\mathrm{e}} \mathrm{s}$., cette production se développe notamment dans de petites unités vinicoles, regroupées dans des quartiers ou hameaux agricoles. Alentours, des fermes de diverses tailles complètent ce dispositif. Certaines présentent des chais surdimensionnés qui illustrent des productions à haut rendement, l'extension des cultures ou encore la concentration des moyens de production (Pomarèdes, 2008 ; Jung, Pomarèdes, à paraître). Dans toute la région, la production de vin se maintient durant le $\mathrm{III}^{\mathrm{e}} \mathrm{s}$. À l'Estagnol ou encore à la Madeleine, cette activité se prolonge 

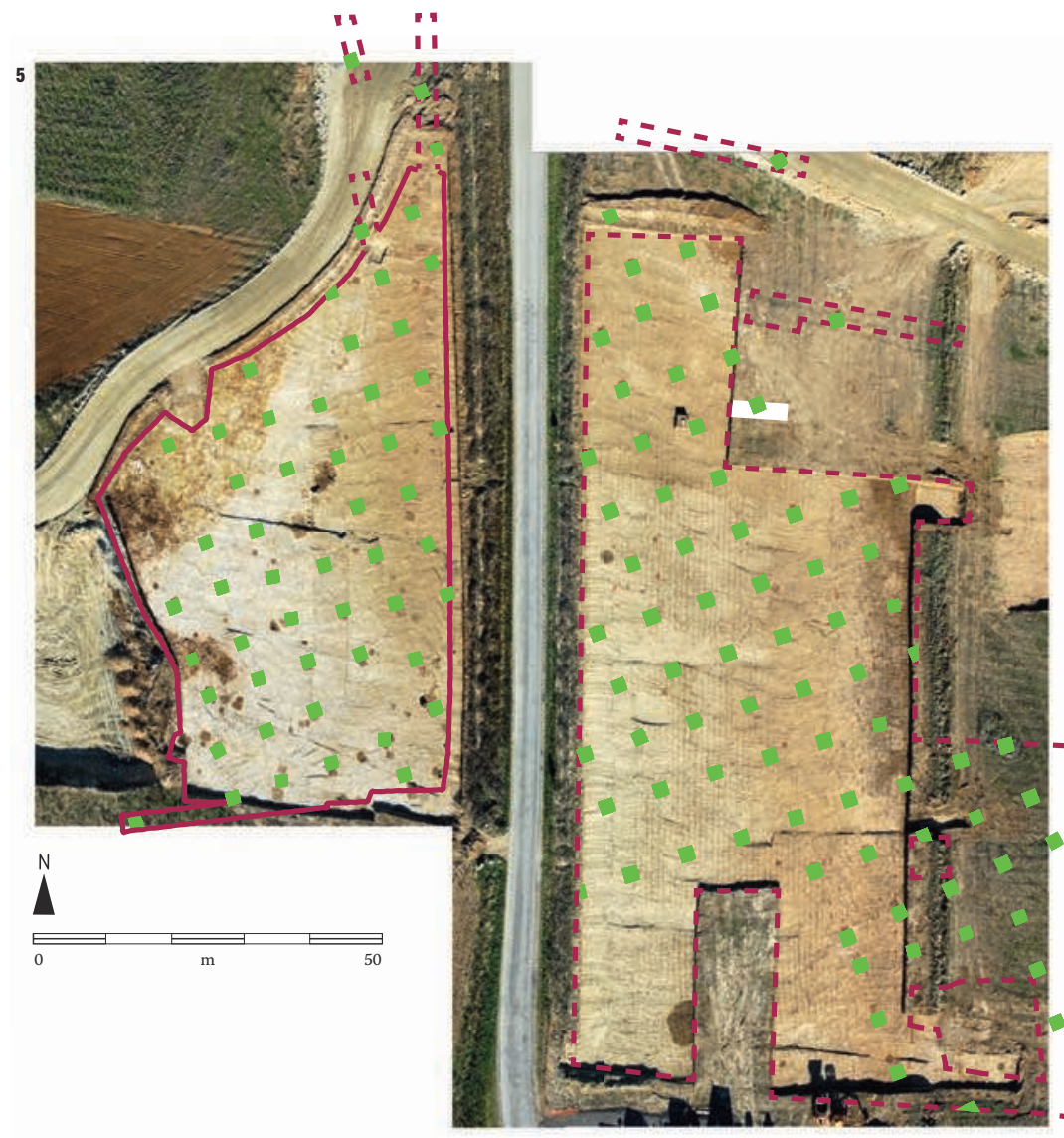

5. Photographie aérienne et plan du verger de Champ Redon à Montblanc. Le maillage des fosses antiques s'étend au moins sur 2,7 ha soit 400 arbres restitués. Ces estimations sont a minima puisque les limites du verger n'ont pas été retrourvées, hormis àl'est, où la trame s'interrompt. Les 1454 tessons retrouvés dans le comblement des fosses datent la plantation fin II' S.-début III' S. ap.J.-C.
6. La ville de Béziers et ses environs immédiats. Les villae carolingiennes localisées sur la rive gauche de l'Orb amorcent une courbe dont les dimensions traduisent le caractère à la fois attractif et répulsif de l'agglomération. En vert, les routes radiantes qui relient la cité aux grandes unités géographiques périphériques; en noir, la voie de "desserte locale" joignant les établissements périurbains.

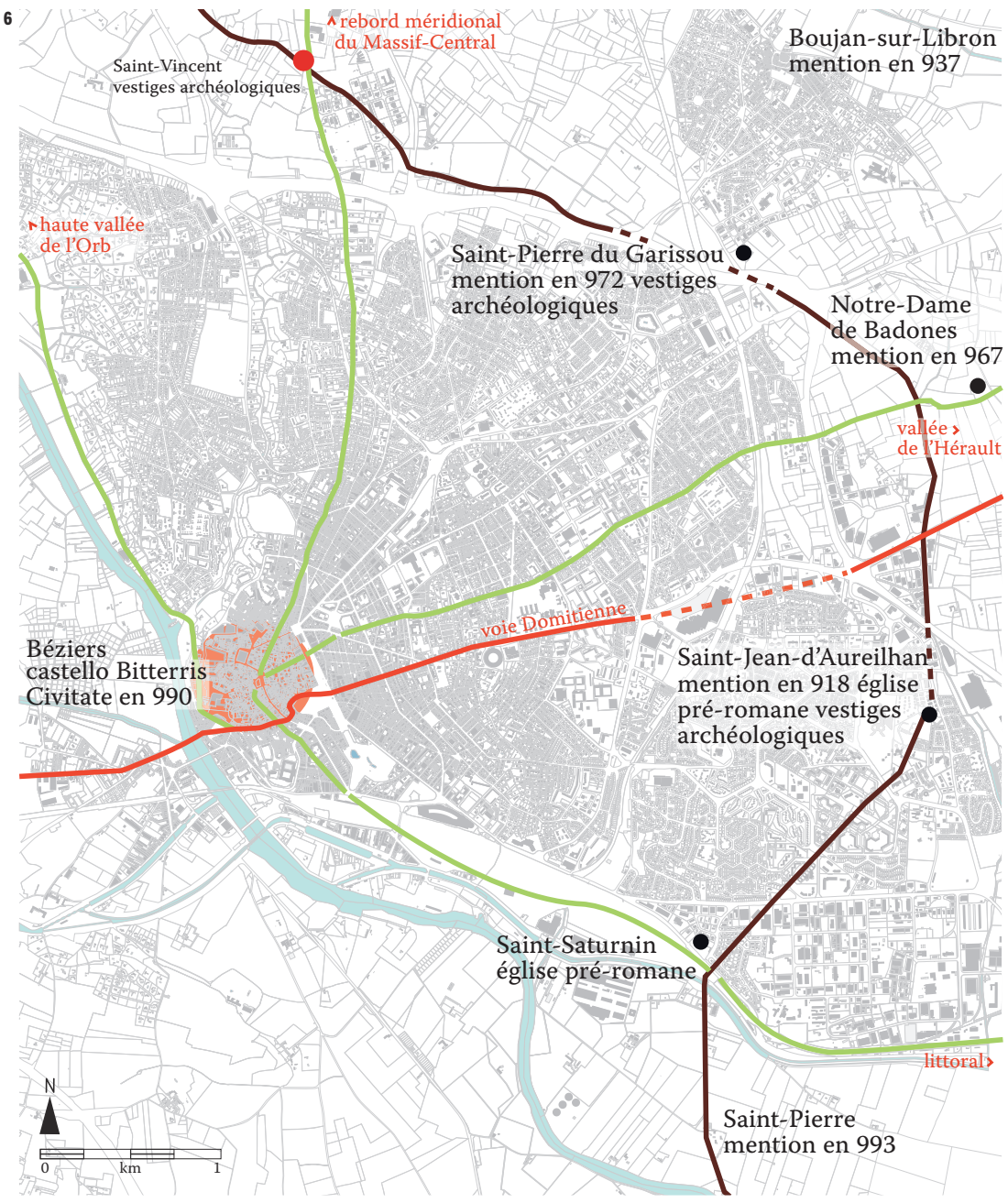


entre les $\mathrm{IV}^{\mathrm{e}}$ et $\mathrm{VI}^{\mathrm{e}}$ siècles. La documentation rassemblée pour le Haut Empire révèle la présence d'un vignoble étendu mais qui trouve une place privilégiée au contact de l'habitat au même titre que d'autres cultures soignées. Les plantations sont relativement standardisées (alvei/fosses allongées et, plus rarement, sulci/tranchées) mais la taille des parcelles de vignes varie nettement, ce qui pourrait refléter la culture de cépages différents et des conduites diversifiées (vigne basse ou hautains, par exemple). Une réflexion approfondie sur la filière viticole peut désormais être engagée. Les plantations formées, au départ, de plants vifs voient le remplacement des pieds manquants comme leur multiplication, par provignage. Par conséquent, la question de l'existence de pépinières et du commerce des plants est posée. Par ailleurs, la variété des cépages que la morphométrie des pépins de raisins met en évidence ${ }^{3}$, notamment sur le domaine de Rec de Ligno (Valros) ou au Gasquinoy (Béziers), témoigne de la culture de la vigne sauvage aux côtés de cépages autochtones (Clairette) et des variétés plus lointaines (Mondeuse blanche, Merlot, Henab-Muscat Petit Grain, Pinot et Petit Verdot). Cette variété illustrerait de possibles importations de boutures.

Plus rarement, l'archéologie agraire met en évidence des vergers et des plantations d'arbres [ill.5]. Le corpus en cours de constitution (Labournas et Champ Redon à Valros ou La Lesse-Espagnac à Sauvian) étoffe avantageusement nos connaissances limitées à l'échelle nationale à deux références: Reims (Marne) (Koehler, 2003) et Roquemaure (Gard) (Barberan et al., 2002). À Valros, deux vergers $\mathrm{du} \mathrm{III}^{\mathrm{e}} \mathrm{s}$. présentent un maillage de fosses de plan carré étendu sur plusieurs hectares. Les conditions édaphiques, le rythme et le module des fosses permettent d'envisager la culture d'oliviers ou d'amandiers. Un troisième verger, probablement irrigué, pourrait marquer la culture de pêchers ou de pruniers. Les analyses anthracologiques et carpologiques réalisées tendent à corroborer ces hypothèses. Malgré les doutes qui subsistent, la diversité des découvertes invite à restituer des productions variées et des récoltes traitées de différentes manières (conserves, ventes sur les marchés locaux ou urbains...). Enfin, les complants et le mariage des cultures sont fréquemment suggérés au regard de l'espacement des rangées de vignes ou d'arbres. Les études botaniques donnent une meilleure idée des rotations de cultures et soulignent, en confrontation avec la géomorphologie et la malacologie, la résilience des paysages mosaïqués (champs et espaces pâturés, bois, écosystèmes humides).

3. Étude réalisée par

le Centre de Bio-

Archéologie et d'Écologie,

UMR 5059 .

4. La plupart dans

le Livre Noir du chapitre cathédral.

\section{L'espace périurbain de Béziers durant le Moyen âge}

En Biterrois et Lodévois, la majorité des établissements gallo-romains fouillés apparaît désertée entre la fin du $\mathrm{II}^{\mathrm{e}}$ (ou le début du $\mathrm{III}^{\mathrm{e}} \mathrm{s}$.) et la fin $\mathrm{du} \mathrm{IV}^{\mathrm{e}} \mathrm{s}$. L'habitat de cette période se concentrerait donc sur un nombre plus restreint de sites parmi lesquels on compte surtout des villae, fondées au I ${ }^{\mathrm{er}} \mathrm{s}$. ap. J.-C. et qualifiées de « sites d'accumulation » ou de " pôles de peuplement ». Entre la fin du $\mathrm{IV}^{\mathrm{e}} \mathrm{s}$. et le $\mathrm{VII}^{\mathrm{e}} \mathrm{s}$., la structure du peuplement s'appuie sur un plus grand nombre d'établissements qui se déploient dans les anciens finages ou encore aux abords des axes de communication (ateliers de potiers, bâtiments d'accueil). La documentation concernant les VIII ${ }^{\mathrm{e}}$ et $\mathrm{IX}^{\mathrm{e}}$ siècles reste trop lacunaire pour permettre une lecture en continue des dynamiques de l'occupation des sols. Au x ${ }^{\mathrm{e}}$ s., Béziers compte déjà près de seize siècles d'histoire urbaine et apparaît comme le fait remarquable d'un territoire dont les composantes demeurent essentiellement rurales. Comme durant l'Antiquité, le suburbium de la ville carolingienne est densément occupé [ill.6]. Les établissements ruraux y sont fréquents et les mentions abondent dans les pages des cartulaires ecclésiastiques ${ }^{4}$. Les siècles qui suivent connaîtront l'apparition d'une nouvelle forme d'occupation des sols, concrétisée par l'émergence de regroupements légèrement perchés et systématiquement enclos. Des sites anciens, occupés pour certains depuis l'Antiquité, seront abandonnés. D'autres deviendront les porte-greffes de nouveaux villages fortifiés.

Les limites de plusieurs villae biterroises ont été urbanisées à partir du début des années 1990. Dans deux cas (villa Fontegarition/Garissou et villa Aureliago/Aureilhan), des fouilles partielles ont pu être engagées. Dès le $\mathrm{x}^{\mathrm{e}} \mathrm{s}$., les chartes évoquent les deux finages qui abritent alors un habitat groupé (in ipsa villa) ainsi qu'un lieu de culte. Aucun des deux, pourtant, ne donnera naissance à un castrum, chacun déclinant dans le courant du bas Moyen Âge. Les études confirment, s'il en était besoin, le caractère agricole des établissements. La production des céréales et des légumineuses est surreprésentée en raison de la présence d'aires d'ensilage dont les dimensions suggèrent la gestion communautaire de récoltes dont une partie était possiblement orientée vers les marchés de la ville proche. D'autres cultures, comme la viticulture, y ont joué un rôle important. Les textes la mentionnent à de nombreuses reprises mais l'archéologie peine encore à la documenter. Les deux villae de Aureliago et de Fontegaritione ont par ailleurs développé certaines activités artisanales. La présence d'ateliers de potiers est avérée sur les deux sites. L'un est daté des XI ${ }^{\mathrm{e}}$-XII ${ }^{\mathrm{e}}$ siècles (Ginouvez, Pomarèdes, 19931994; Gomez, 2010), l'autre de la première moitié du XIII ${ }^{\mathrm{e}}$ siècle ; la courte activité de ce dernier pourrait traduire une « production de crise» immédiatement postérieure à la croisade des Albigeois (Lécuyer, 2010). Aucune maison, fut-elle unitaire ou complexe (mansus cum curte), n'a été encore mise au jour et l'on attend impatiemment le premier plan qui permettra enfin d'envisager l'organisation d'un habitat précastral.

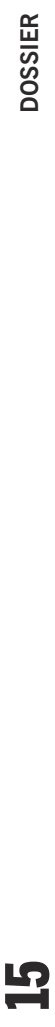



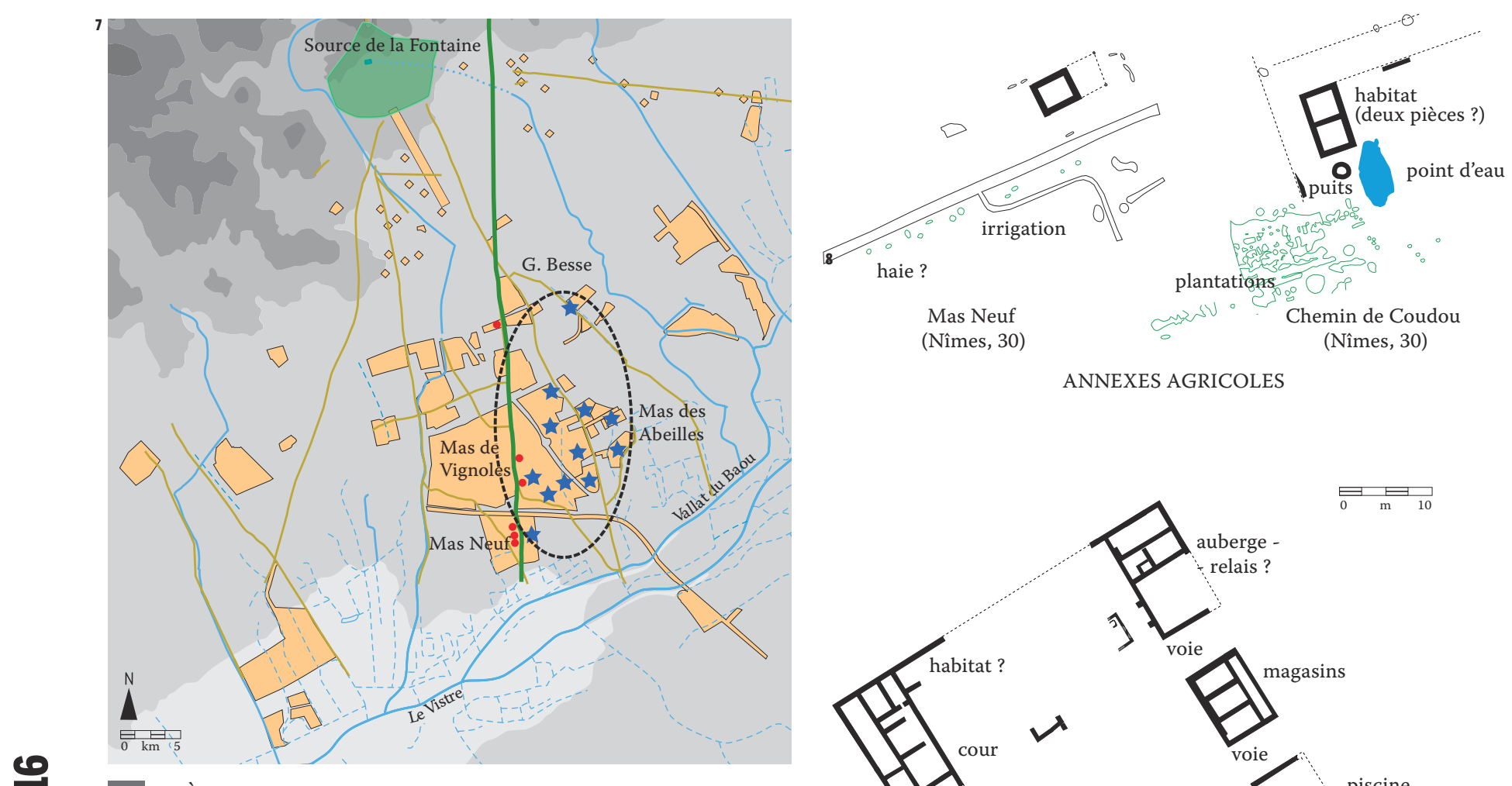

150 à $175 \mathrm{~m}$ 125 à $150 \mathrm{~m}$ 100 à $125 \mathrm{~m}$ 75 à $100 \mathrm{~m}$ 50 à $75 \mathrm{~m}$ 25 à $50 \mathrm{~m}$ Contour des opérations Axe de circulation VIII ${ }^{\mathrm{e}}-\mathrm{VII}^{\mathrm{e}}$ s. av. J.-C. Axe de circulation $\mathrm{VI}^{\mathrm{e}}-\mathrm{III}^{\mathrm{e}}$ s. av. J.-C.

- Emprise restituée de l'habitat VIII ${ }^{\mathrm{e}}-\mathrm{VII}^{\mathrm{e}}$ s. av. J.-C.

Ensembles sépulcraux VIII $^{\mathrm{e}}-\mathrm{VII}{ }^{\mathrm{e}}$ S. av. J.-C.

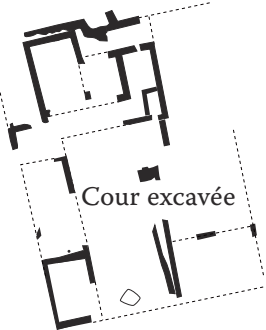

Courbessac (Nîmes, 30)

Concentrations de vestiges $\mathrm{VIII}^{\mathrm{e}}-\mathrm{VII}^{\mathrm{e}} \mathrm{s}$, av. J.-C.

Limites de l'agglomération fin $\mathrm{VI}^{\mathrm{e}}-\mathrm{V}^{\mathrm{e}}$ s. av. J.-C.
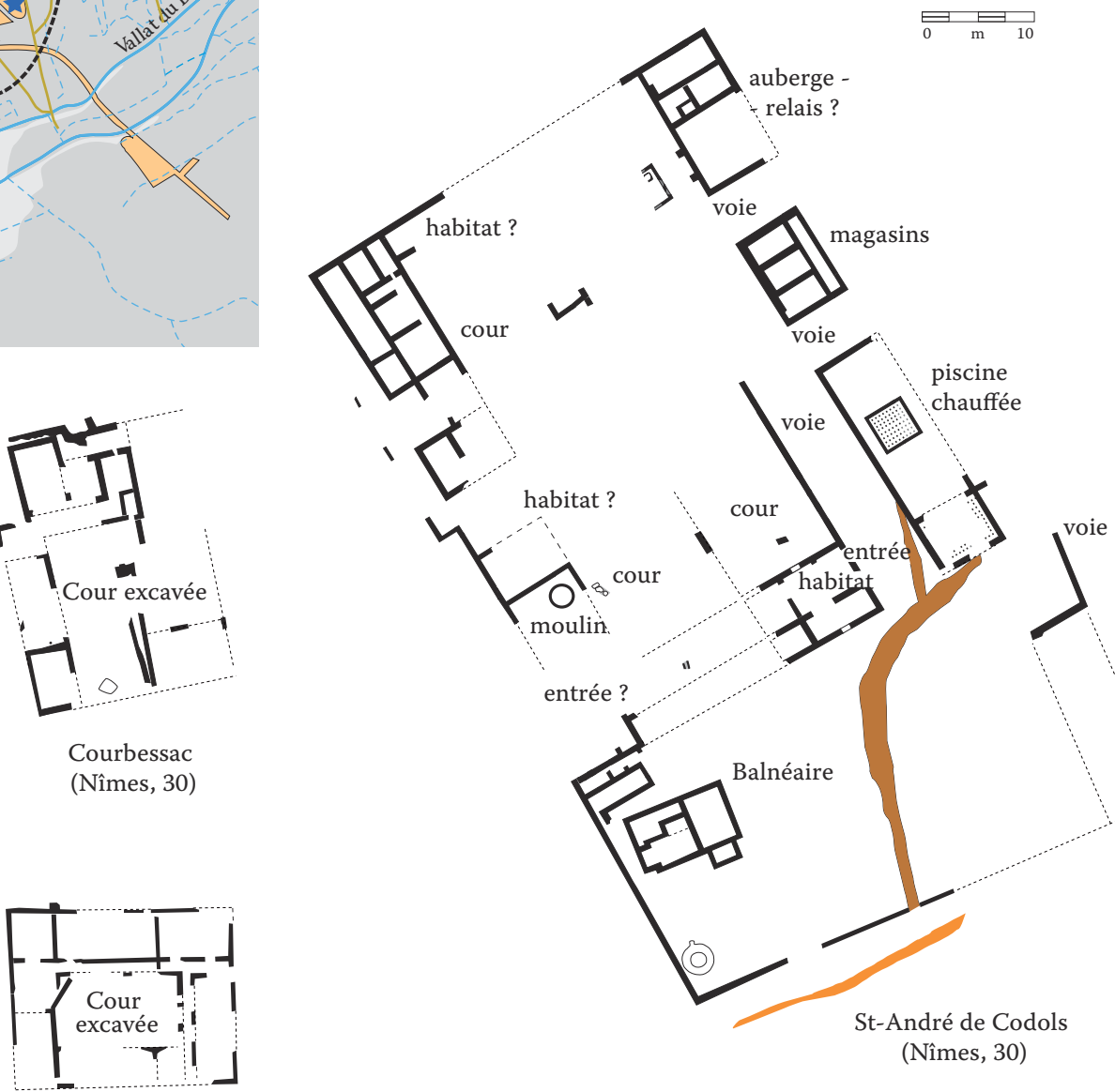

ANNEXES AGRICOLES

Gouffre des Bouchers (Nîmes, 30)

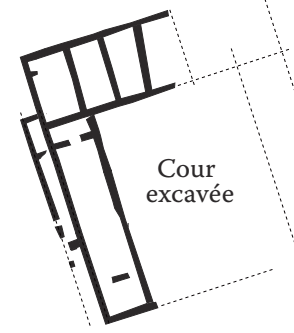

Mas de Mayan (Nîmes, 30)

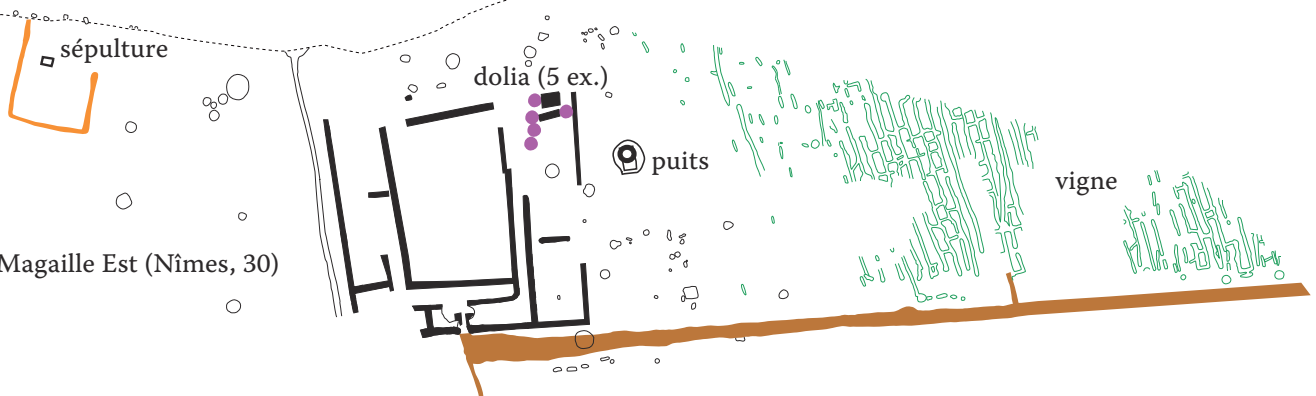


7.L'extension de l'habitat des ViII' et vile S. av. J.-C. dans la plaine de Nîmes. 8. Formes de l'habitat rural gallo-romain de la périphérie de Nîmes. Les fermes familiales à cour centrale (excavée) se distinguent des petits habitats et des annex (Mas Neuf et Chemin de Coudou) comme des grands établissements de La Condamine (Millau) ou de Saint-André de Codols (II' S. ap. J.-C.). Au "II' S., la surface de Saint-André de Codols sera doublée, passant de $6000 \mathrm{~m}^{2}$ à1,2 ha. Une villa palatial à cour centrale et à étages, siège d'une vaste propriété, y sera installée.
Du fait d'un opportunisme sans doute proportionnel à la proximité qu'elles entretenaient avec le chef-lieu de cité, les villae périurbaines ont pu investir dans des sources de revenus conformes aux demandes permanentes de la ville en produits alimentaires et manufacturés. Le stimulus exercé sur la frange rurale de l'agglomération a ainsi motivé l'entretien d'exploitations qui ne seront pas concernées par le processus castral (trop proches de l'enceinte) et perdront ainsi leur rôle d'habitat au profit d'un mode de fonctionnement orienté vers la seule production agricole.

\section{L'espace nîmois \\ Le développement du peuplement et de l'économie agricole protohistoriques autour de l'oppidum nîmois}

En Languedoc oriental, la recherche en Protohistoire a, peu ou prou, suivi les inflexions décrites pour le Languedoc occidental. L'étude des oppida de l'arrière-pays et des occupations lagunaires a été prépondérante jusque dans les années 1990 (Py, 1990). Ces publications ont constitué un socle de référence du point de vue des approches économiques et de la connaissance des mobiliers. L'archéologie préventive a permis d'accéder aux espaces de plaine, jusqu'alors investis par les seules prospections, confirmant la présence d'occupations très diverses et donnant lieu à un renouvellement des problématiques sur la mise en valeur du sol (Sauvage, 1996). À partir des années 200o, l'accroissement du nombre d'opérations a favorisé l'étude pluridisciplinaire des territoires, notamment autour des agglomérations de Lattara (Lattes) et Nîmes dont les origines se situent aux alentours de 500 av. notre ère. Le paysage rural de la plaine nîmoise a un double héritage : un impact anthropique ancien dès le Néolithique moyen et une paléotopographie ondulée, héritée des cours d'eau qui drainent les violentes précipitations vers le Vistre et qui génèrent au gré des talwegs et interfluves une mosaïque de sols (Chevillot et al., 2010). Les vestiges y sont appréhendés comme autant de témoins d'interactions entre monde rural et faits urbains ; considérant que l'agriculture joue un rôle socio-économique majeur entre producteurs, négociants et consommateurs et comme facteur d'ouverture vers la sphère méditerranéenne (Séjalon et al., 2009). À l'échelle des microrégions étudiées, il est tout de même difficile d'appréhender ces problématiques pour la totalité de la période considérée. En effet, les occupations sont très rarement documentées selon un continuum chronologique, et de nombreux hiatus évoquent plutôt des abandons, des déplacements ou des restructurations.

En comparaison avec le nombre important d'oppida de la fin du $\mathrm{VI}^{\mathrm{e}}$ et du $\mathrm{V}^{\mathrm{e}} \mathrm{s}$. av. notre ère, on note, par exemple, une quasi absence des sites perchés au VII ${ }^{\mathrm{e}}$ et au début $\mathrm{VI}^{\mathrm{e}}$. Ce déficit difficilement compréhensible, trouve un début d'explication à Nîmes. Un vaste habitat de plaine y est mis en évidence grâce à l'étude de vestiges épars mais récurrents, observés à l'occasion de nombreux diagnostics [ill.7], et à celle des mobiliers. Sur plusieurs dizaines d'hectares s'organiserait un premier regroupement des populations. Le schéma qui se dégage montre qu'au milieu des espaces agricoles ceinturés par des fossés curvilignes, se trouvent les espaces dédiés à la maison et au stockage. Ce vaste établissement est installé à proximité d'un très long axe de circulation, reliant les garrigues au littoral, dont l'origine ancienne peut être liée au parcours des troupeaux. Ses abords semblent aussi le lieu privilégié de l'installation de quelques ensembles funéraires. Après un vide documentaire qui couvre les trois premiers quarts $\mathrm{du} \mathrm{VI}^{\mathrm{e}} \mathrm{s}$. av. notre ère, on enregistre un déplacement de $3 \mathrm{~km}$ de la population vers la colline du Mont Cavalier au pied duquel se situe la Source de la Fontaine. On attribue ce mouvement au rôle prépondérant de cette source comme sanctuaire topique qui attire à elle un nouveau réseau de chemins mettant en relation les principaux établissements de la région.

Dès la fin $d u v^{\mathrm{e}}{ }^{\text {et }}$ au début du $\mathrm{V}^{\mathrm{e}} \mathrm{s}$. av. notre ère, on perçoit le développement d'un nouveau système agricole. Dans l'habitat groupé du Mont Cavalier qui n'est pas encore fortifié, les témoins de cultures en terrasses, d'amendements des sols et de stockage des céréales sont mis en relation avec un tissu d'habitats assez lâche et peu structuré. En parallèle se développe dans la plaine un réseau d'exploitations agricoles qui se déploie sur 2 à $4 \mathrm{~km}$ de profondeur. La fouille de plusieurs de ces exploitations (Mas de Vignoles IX et Mas de Vigier à Nîmes) a révélé une partie de leurs activités. Si l'agriculture céréalière demeure une composante importante, l'élevage tient une place non négligeable, notamment celui du cheval qui semble être une spécificité locale. La répartition de ces exploitations permet d'évaluer la superficie de leur finage. D'après les études des mobiliers, on envisage que ces exploitations généraient des surplus propices aux échanges et à l'acquisition de biens en provenance de Méditerranée, comme le cratère attique à figures rouges (425-400 av. n. è.) découvert sur le site de Mas de Vignoles IX à Nîmes. Se distingueraient ainsi une agriculture vivrière, pratiquée au cœur même de l'agglomération du Mont Cavalier, et une agriculture extensive, susceptible de fournir des surplus commercialisables.

À partir du IV ${ }^{\mathrm{e}}$ s. av. notre ère, on enregistre de nombreuses mutations. L'habitat groupé se concentre derrière une fortification composée d'un rempart et d'une tour monumentale, sur la colline du Mont Cavalier, et d'un large fossé, installé sur le piémont, qui englobe la source de la Fontaine. Les maisons sont construites en dur et les premières formes d'urbanisation apparaissent. En conséquence, la surface des cultures diminue intra muros. Aux abords du fossé, les premières plantations de vigne attestent l'appropriation de techniques agricoles méditerranéennes laissant supposer une production 


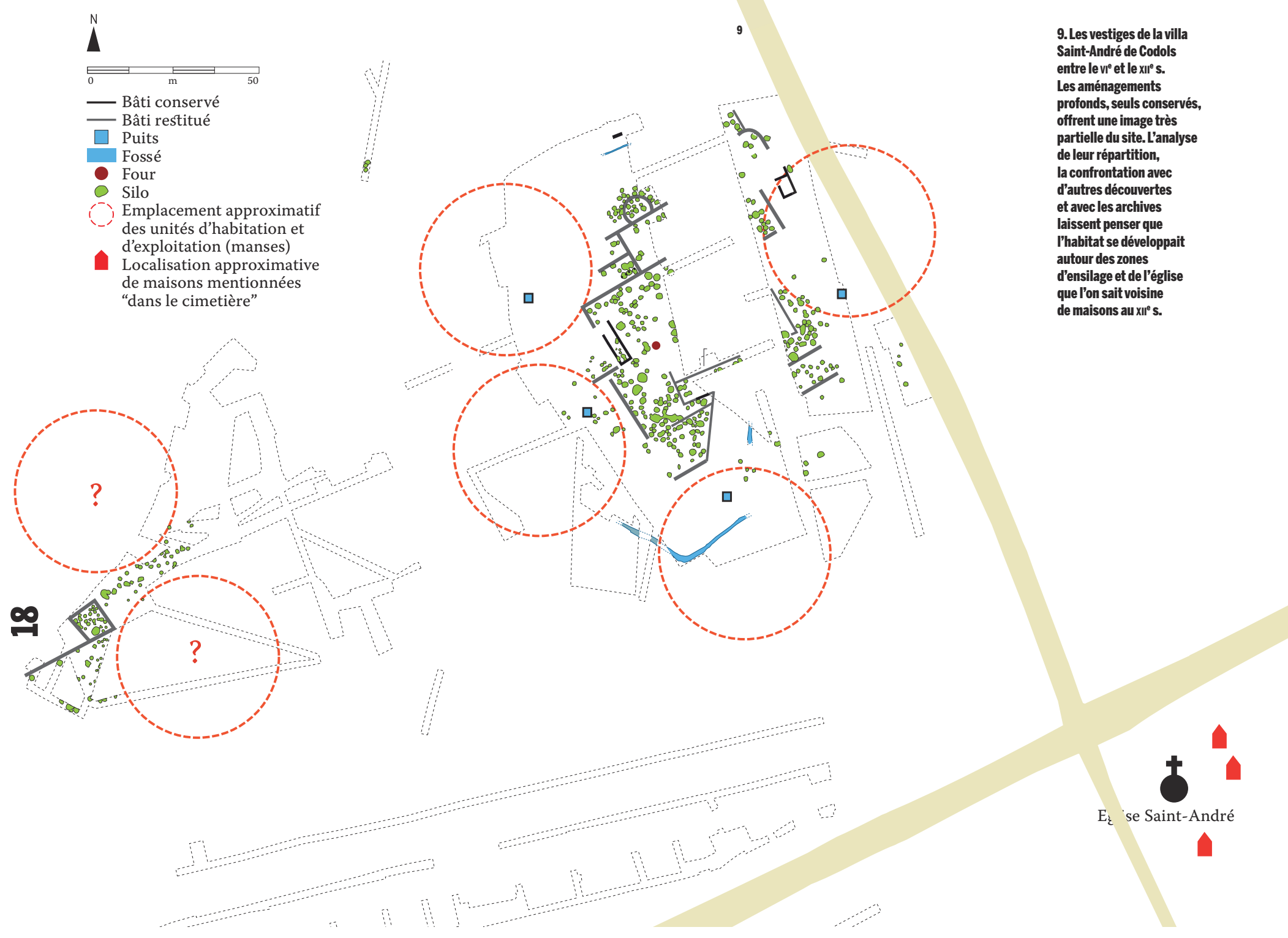

de vin indigène (fouilles du Parking Jean-Jaurès à Nîmes). En plaine, si le nombre d'exploitations se réduit, leur taille augmente et de nouveaux espaces semblent conquis. Cette dynamique qui mérite d'être analysée en détail, se heurte aux hypothèses de crise encore très largement répandues pour la partie occidentale de la région.

Ces mutations qui affectent autant la ville que les campagnes s'accélèrent aux $\mathrm{II}^{\mathrm{e}}-\mathrm{I}^{\mathrm{er}} \mathrm{s}$. av. notre ère. Le périmètre urbain s'agrandit légèrement, de nouvelles voies sont édifiées en périphérie de la ville et en plaine, parfois sur des tracés plus anciens. Le développement des premiers faubourgs résidentiels et artisanaux repousse les parcelles plantées en vigne ou dévolues à des cultures irriguées. À 2 km de l'agglomération, les exploitations agricoles fouillées à Magaille Est ou au Gouffre des Bouchers (Pomarèdes, Breuil, 2006) sont de grande taille ( 0,8 à 1,2 ha) et leurs plans, scandés par de profonds fossés et par des enclos, témoignent d'un découpage complexe et d'activités variées (viniculture, élevage, artisanats). Ces dernières génèrent autour d'elles de vastes parcellaires agricoles et pourraient correspondre à d'importantes exploitations domaniales.

Entre les $\mathrm{VI}^{\mathrm{e}}$ et $\mathrm{I}^{\mathrm{er}} \mathrm{s}$. av. notre ère, dans la campagne nîmoise, les implantations funéraires sont disséminées le long des voies et sont constituées de sépultures isolées ou de petits groupes de tombes (Bel et al., 2008 ; Bel et al., 2010). Certains ensembles, fréquentés longuement, n'accueillent qu'une tombe par génération ce qui témoigne d'un recrutement sélectif. Aux enclos fossoyés circulaires ou rectangulaires, succèdent, à partir du $\mathrm{II}^{\mathrm{e}} \mathrm{s}$. av. notre ère, des espaces ouverts, implantés à distance des habitats, dans des secteurs plantés de vignes. La période tardo-républicaine est marquée par une multiplication de ces espaces sans que l'on note un développement significatif de l'habitat rural. Il est donc possible qu'une partie des tombes appartienne à des groupes résidant dans l'agglomération. Leur localisation au sein des terroirs 
mis en valeur, le caractère ostentatoire de la plupart des tombes et la fréquence des armes témoignent cependant de l'assise guerrière et foncière de ces groupes qui pourraient être les propriétaires des terres sur lesquelles leurs tombes ont été établies. Les implantations funéraires pourraient ainsi manifester l'emprise de la ville et de ses élites sur la campagne environnante.

\section{L'espace périurbain nîmois durant l'Antiquité}

Â partir de l'époque augustéenne, les équilibres entre ville et campagne sont fortement modifiés par le développement sans précédent de l'agglomération. La nouvelle enceinte délimite un espace de plus de 200 ha, cinq fois plus vaste que le précédent, englobant au nord et à l'ouest des collines calcaires qui ne seront pas urbanisées et consommant au sud et à l'est les terres les plus fertiles du suburbium. Plusieurs fouilles (ZAC des Halles, Florian, Parking Jean-Jaurès) ont ainsi montré la présence de traces de vignobles protohistoriques et de dispositifs d'irrigation $\mathrm{s}$ ous les quartiers neufs gallo-romains.

Dans la plaine, les recherches ont permis de s'interroger sur la diversité des régimes et des systèmes agraires nîmois en lien avec ce phénomène et replacés dans un contexte régional d'expansion de l'occupation du sol et d'affirmation de la viticulture. Au début mais surtout au milieu du $\mathrm{I}^{\mathrm{er}} \mathrm{s}$. ap. notre ère, le peuplement s'épanouit dans l'ensemble des terroirs périurbains et prend diverses formes. La très proche campagne devient un lieu de mobilité et d'activités variées (artisanat, stockage, dépotoirs...) et met en scène les accès à la Colonia Augusta Nemausus (arc de triomphe, organisation des espaces funéraires...) (Pomarèdes et al., à paraître). Plus loin, on compte de petites annexes agricoles jouant le rôle de relais pour des sièges de propriétés plus éloignés, comme peut l'être la domus urbaine [ill.8]. De petits habitats ont également été découverts. Leur taille (quelques dizaines de mètres carrés) et la surface de leur finage apparaissent très réduites, ce que justifierait le caractère intensif de l'agriculture locale. L'usage de l'irrigation complété par l'emploi de fumures conduit à l'hypothèse du développement dans ces petites exploitations, de cultures soignées (horticulture, maraîchage), mais aussi de productions intensives de céréales ou de légumineuses.

La croissance urbaine du Ier s. aurait donc pour corollaire l'extension dans la plaine de l'auréole vivrière et la recherche d'une rentabilité accrue grâce à l'emploi des engrais en provenance de l'agglomération.

Des fermes familiales plus importantes (6oo à $800 \mathrm{~m}^{2}$ ), autour desquelles on perçoit l'accroissement des surfaces du vignoble, témoignent d'investissements à caractère spéculatif. Celles qui ont pu être étudiées sont organisées autour d'une cour centrale particulière, excavée sur plusieurs dizaines de centimètres de profondeur, qui traduit une adaptation aux conditions édaphiques de la plaine fortement soumise aux fluctuations des nappes phréatiques. Si elles apparaissent assez rustiques de prime abord, les mobiliers collectés dans le comblement des cours (colonnes, chapiteaux, stèles, statuaire, verres, objets de toilettes, amphores importées de plusieurs provinces de l'Empire) autorisent à penser qu'elles jouissent d'un certain confort et qu'elles sont entretenues longuement, jusqu'au milieu ou la fin du $\mathrm{III}^{\mathrm{e}} \mathrm{s}$. pour certaines.

Une autre forme de réponse à la vitalité de la demande urbaine est perceptible dans la création de grands établissements, cependant moins nombreux, pouvant traduire certaines initiatives des élites locales. Le premier établissement de Saint-André de Codols, occupant plus de $6000 \mathrm{~m}^{2}$ $\mathrm{au} \mathrm{II}^{\mathrm{e}}$ s., en serait un exemple et ses installations (auberge, balnéaire de bord de voie) comme son activité de boucherie (bovins) lui confèrent des fonctions particulières. La villa, au caractère aristocratique affirmé, qui lui succède au début $\mathrm{du} \mathrm{III}^{\mathrm{e}} \mathrm{s}$. marquerait une nouvelle période d'épanouissement du régime agraire domanial (viniculture, céréaliculture, boucherie). On y restitue sur plus d'1 ha, de vastes appartements étagés, de grands entrepôts et des salles de réception, organisés autour d'une cour de près de 4 . ooo $\mathrm{m}^{2}$ (Pomarèdes dir., à paraître). L'épanouissement de cette villa est aujourd'hui confronté à d'autres processus contemporains, notamment l'étiolement du tissu urbain et l'essoufflement du modèle de la domus, traditionnellement associé à l'effacement d'une partie des élites locales.

\section{L'évolution des paysages urbain et rural entre $v^{e}$ et $X{ }^{\prime} I^{e}$ siècles}

Entre les $\mathrm{V}^{\mathrm{e}}$ et $\mathrm{x}^{\mathrm{e}} \mathrm{s}$., le paysage se transforme à nouveau. En ville, le processus de résorption du tissu urbain amorcé au $\mathrm{II}^{\mathrm{e}} \mathrm{S}$., aboutit à la ruralisation de l'espace et à la concentration de l'habitat en quelques pôles. Le plus grand se forme autour de la cathédrale, peut-être dès le $\mathrm{IV}^{\mathrm{e}} \mathrm{s}$. Le second, fortifié au $\mathrm{VI}^{\mathrm{e}} \mathrm{S}$., se développe dans l'amphithéâtre. D'autres sont supposés sur le forum antique et les principales portes du rempart gallo-romain. Les pôles principaux s'étendent jusqu'à se rejoindre au XIII ${ }^{\mathrm{e}} \mathrm{s}$. Le noyau urbain, alors unifié, est à son tour fortifié au XIV ${ }^{\mathrm{e}} \mathrm{s}$. par un mur qui signe l'abandon du rempart antique. En périphérie de la ville, les fouilles livrent peu de vestiges médiévaux. Très érodés par les travaux agricoles du $\mathrm{Xx}^{\mathrm{e}} \mathrm{s}$., les habitats du haut Moyen Âge sont abordés de manière pluridisciplinaire, dans la perspective d'une meilleure caractérisation de leurs formes, de leur économie et de leur environnement. Ainsi, sur le site du Mas de Vignoles XIV, des cultures de la vigne, du chanvre et du lin sont identifiées et associées à des dispositifs hydrauliques servant vraisemblablement au rouissage des fibres textiles.

La convergence de certaines découvertes amène par ailleurs le développement de recherches particulières à l'image de celle portant sur la gestion des eaux et confrontant fossés, conduites, puits 
et puisards à la terminologie des textes et aux conditions édaphiques des sites (Maufras et al., 2011). Plus largement, la connaissance de l'occupation du sol s'appuie sur les données d'archives. Les questions de chronologie et d'évolution du peuplement sont posées dorénavant en systématisant les croisements entre céramologie, fossiles directeurs et mesures du radiocarbone (Maufras et al., à paraître a). Les données récemment acquises restituent l'évolution de l'occupation du sol nîmois dans ses grandes lignes.

Les abandons observés sur les habitats ruraux $\mathrm{au} \mathrm{IV}^{\mathrm{e}}$ et $\mathrm{au} \mathrm{V} \mathrm{V}^{\mathrm{e}} \mathrm{s}$. ne signalent pas leur désertion mais la réorganisation des domaines agricoles. Ainsi, à Carsalade (Nîmes), les silos et les sépultures installés sur les ruines d'un établissement antique montrent le maintien des cultures et de l'habitat jusqu'au IX ${ }^{\mathrm{e}} \mathrm{s}$. De même, la villa gallo-romaine de Carreiron-et-Pesquier (Millau) devient-elle, au $\mathrm{VI}^{\mathrm{e}} \mathrm{s}$., le quartier d'ensilage d'un habitat situé à $500 \mathrm{~m}$ plus au nord.

Dans le cadre d'un parcellaire et d'un réseau viaire hérités de l'Antiquité, la structure de l'habitat se modifie. Le haut Moyen Âge ne connait plus de grands établissements à l'image des villae galloromaines. Une multitude d'unités d'exploitation émerge : les manses. Ils se composent de parcelles accueillant le bâti, de cours et de jardins. Le plus souvent, ils sont groupés en agglomérations qui prennent le nom de villa. Ces habitats sont progressivement dotés d'une église et d'un cimetière, parfois d'une tour de défense. Saint-André de Codols en est un exemple. La cour de l'ancienne villa est dévolue à l'ensilage et entourée d'au moins quatre manses révélés par leurs puits, un four, quelques murs et des dépotoirs [ill.9]. Le petit établissement indépendant créé au Ve s. au nord de la villa antique est peut-être le premier d'entre eux. Il témoignerait d'une première étape de morcellement de la grande propriété antérieure. La villa médiévale de Codols était vraisemblablement très étendue. Nous la restituons sur un minimum de 10 ha, autour de plusieurs aires d'ensilage et jusqu'au carrefour routier qui dessert son église et son cimetière (Maufras et al., à paraître b). En plaine du Vistre, les villae du haut Moyen Âge forment un maillage dense qui est en place au $\mathrm{x}^{\mathrm{e}} \mathrm{s}$., et se maintient jusqu'à ce qu'au XIII ${ }^{\mathrm{e}} \mathrm{s}$., l'incastallamento ne modifie à nouveau les formes et le réseau de l'habitat.

Les travaux présentés dans cet article s'appuient sur des sites et des données de natures diverses qui offrent in fine des perspectives de recherches pluridisciplinaires. ${ }^{\mathbf{5}}$. Le renouveau de la documentation contribue tout d'abord à préciser certains aspects de l'évolution des formes des établissements, ruraux ou périurbains, et éclaire la délicate question de l'organisation du peuplement et des réseaux. Du milieu de l'âge du Bronze final au début du premier âge du Fer, les formes de l'habitat restent difficiles à caractériser hormis, si on excepte les installations découvertes submergées dans l'étang de Thau. Seules quelques unités domestiques, associées à des aires de stockage excavées, sont connues. Au milieu du premier âge du Fer, entre les VIII ${ }^{\mathrm{e}}$ et VII ${ }^{\mathrm{e}}$ siècles, on note la constitution de vastes ensembles dont l'organisation serait assez lâche. Ils pourraient s'étendre sur plusieurs dizaines d'hectares. Cette tendance s'interromprait au cours du $\mathrm{VI}^{\mathrm{e}} \mathrm{s}$., lorsque, en corollaire de la création des oppida, apparaît une nouvelle catégorie de sites méritant alors pleinement l'appellation d'établissement rural, en confrontation au monde urbain en gestation. Ces habitats se déploient majoritairement en périphérie de ces nouvelles agglomérations, manifestation probable d'un rapport hiérarchique, que l'on ne sait pas encore définir précisément, et d'une nouvelle mise en valeur des sols. D'autres sont plus éloignés, trahissant vraisemblablement un statut et une appropriation de l'espace différents. La fin de l'âge du Fer se caractériserait par la création d'habitats dont les formes évoquent celles des fermes continentale et atlantique. Plus grands et souvent insérés dans un ou plusieurs enclos, certains d'entre eux correspondraient à cette époque (mais sans doute est-ce déjà le cas précédemment?) à de vastes exploitations accueillant une élite foncière. Dans ces contextes, les premières attestations de la culture de la vigne permettent de saisir certains signes d'acculturation et le développement des échanges.

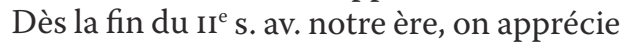
le développement de cette viti-viniculture régionale. Les recherches en géo-archéologie, en paléo-écologie et en botanique permettent d'en préciser les modalités et reconnaissent, à l'amorce du $\mathrm{I}^{\mathrm{er}} \mathrm{s}$. ap. notre ère, d'autres productions qui illustrent la diversité des systèmes agraires et la vitalité de la polyculture, dynamisées par la demande croissante des populations, notamment urbaines. Les grandes exploitations domaniales du Biterrois, les agglomérations d'agriculteurs et de vignerons de la vallée de l'Hérault comme les nombreuses fermes de l'ensemble de nos régions vont alors s'épanouir et se combiner pour assurer durablement leur approvisionnement et prendre part à un commerce régional qui reste florissant jusqu'au cœur du $\mathrm{III}^{\mathrm{e}} \mathrm{s}$. À la fin de l'Antiquité, les modes d'exploitation des sols apparaissent tout aussi diversifiés. Dans certaines grandes villae, auxquelles on associe concentration foncière et programmes architecturaux ostentatoires, les outils de production et les capacités de stockage sont renouvelés, parfois jusque dans la seconde moitié du $\mathrm{V}^{\mathrm{e}} \mathrm{s}$. Les fermes de taille plus modeste présentent une moindre stabilité et leurs composantes se diversifient : cernant l'habitat, pièces excavées, palissades. D'autres formes d'occupation, de lecture souvent délicate, apparaissent durant le Haut Moyen Âge. Les établissements prennent progressivement la taille d'unités familiales et se concentrent en un point ou deux du finage, donnant naissance aux premières formes villageoises. Ces habitats groupés accueillent très tôt une église, qui contribuera ensuite à leur polarisation, et des équipements dont la gestion paraît communautaire (cimetière et aires d'ensilage). remerciements à I.

Figueiral (Inrap, UMR 5059), V. Forest (Inrap, UMR 5608), C. Jorda Martin (Inrap, UMR 5140) et P. Rascalou (Inrap, UMR 5140) 
Ces sites sont ouverts, étendus et non fortifiés, mais certains peuvent être dotés d'une tour. En Languedoc, ils deviennent chefs-lieux paroissiaux, mais à la périphérie de Nîmes, ils restent attachés à la paroisse urbaine, celle de la cathédrale. La compréhension de l'espace rural ne peut donc se limiter à la seule analyse des sites perçus individuellement. Elle s'appuie également sur la confrontation avec les agglomérations proches, les formes de la ruralité étant souvent liées aux dynamiques urbaines. La mise en réseau de tous les éléments qui façonnent le paysage rural éclaire cette géo-diversité des territoires et fait apparaître une réalité plurielle du monde rural (agraire, économique, sociale et culturelle...).

\section{Références bibliographiques}

Barberan S., Fabre L., Maufras O., Petitot H., Pomarèdes H., Sauvage L., Thernot R., 2002 : "Les villae de La Ramière à Roquemaure, Gard », in, COLLECTIF, (DIR.), Archéologie du TGVMéditerranée, Fiches de synthèse. Tome 3 : Antiquité, Moyen âge, Epoque moderne, Lattes, ADALR, (coll. Monographies d'Archéologie Méditerranéenne, 10), p. 889-919.

Bel V., Barberan S., Chardenon N., Forest V. Rodet-Belarbi I., Vidal L., 2008 : Tombes et espaces funéraires de la fin de lâge du Fer et du début de l'époque romaine à Nîmes (Gard), Lattes, ADALR, (Monographies d'Archéologie Méditerranéennes, 24), 519 p.

Bel V., Barberan S., Chardenon N., 2010 : « Les pratiques funéraires dans la province de Gaule Transalpine " in, Barral P., Dedet B., Delrieu F., Giraud P., Le Goff I., Marion S., Villard-Le Tiec A., (Dir.), Gestes funéraires en Gaule au Second âge du Fer Actes du XXXIII colloque international de l'AFEAF, Caen, 20-24 mai 2009, Besançon, Presses universitaires de Franche-Comté, (coll. Annales littéraires, 883 série « Environnement, Sociétés et Archéologie », 14), p. 311-325.

BEL V., GLEIZE Y., à paraitre : « La Vigne-de-Bioaux à Valros (Hérault, France), un ensemble funéraire atypique en Gaule Narbonnaise : discussion et interprétation des données archéo-anthropologiques ", in, CAstex D., Gleize Y., (DIR.), Actes de la session "Social identity during the Roman Antiquity in western Mediterranean sea : mortuary practices and organization of the funerary space", colloque international de l'EAA, Riva del Garda, Trento, Italy, septembre 2009, Montagnac, Monique Mergoil

Chevillot P., Martin S., Breuil J.-Y., Pomarèdes H., Sejalon P., 2010 : « Mobilités et héritages dans la plaine de Nîmes (Gard, France), Regards croisés sur l'occupation humaine à l'Holocène », in, Actes du colloque AFEQ-INQUA "Q6 - Biodiversité du Quaternaire: Climats, Environnements et Peuplements ", Montpellier, 26-28 février 2008, Quaternaire, 21/4, Paris, Association Française pour l'Etude du Quaternaire, p. 459-474.

Ginouvez O., Pomarèdes H., 1993-1994 : « Premières observations sur le site de Saint-Jean-d'Aureilhan. Pour une contribution à létude des campagnes biterroises durant l'Antiquité et le Moyen Age », Bulletin de la Société Archéologique de Béziers, Septième série, Volume V, p. 3-14.

GOMEZ E., 2010 : «Contribution à la caractérisation des productions potières médiévales de Béziers », in Bourin M., (DIR.), Autour du sac de Béziers. Richesses et malheurs en Languedoc au XIII ${ }^{\text {s }}$ siècle, colloque de Béziers (4 et 5 juin 20o9), Perpignan, Presses Universitaires de Perpignan, p. 241-252.

JuNG C., BEL V., (DIR.), 2010 : Autoroute A75, Section BéziersPézenas, Hérault, Montblanc et Valros, Aire de Repos de Valros, Occupations d'un espace rural antique dans le territoire de la ville de Béziers, Rapport final d'opération de fouille archéologique, Nîmes, Inrap.

Jung C., Pomarèdes H., avec la collab. de Compan M. Figueiral I., Ginouvez O., Martin S., Tardy C, à paraître : «Des pratiques culturales et des systèmes agraires antiques en vallée de l'Hérault et Biterrois (Hérault, Languedoc-Roussillon, France) », in Actes des Rencontres d'archéobotanique de Montpellier (Hérault), 13-16 octobre 2010, Plantes produits et pratiques : diffusion et adoption de la nouveauté dans les sociétés préindustrielles, Montpellier.

KoEHLER A., 2003 : « Vergers antiques dans les campagnes périurbaines : le cas de Reims ", in, LEPETZ S., MAtTerne V., (ÉD.), Cultivateurs, Éleveurs et artisans dans les campagnes de Gaule romaine, matières premières et produits transformés, Actes du VI ${ }^{\mathrm{e}}$ colloque de l'association AGER de Compiègne (Oise), 5 au 7 juin 2002, Revue Archéologique de Picardie, 1/2, 2003, p. 37-46.

LECUYER N., 2010 : «Un atelier de potiers au Garissou. Une production de crise? », in BourIN M. (DIR.), Autour du sac de Béziers. Richesses et malheurs en Languedoc au XII' siècle, colloque de Béziers (4 et 5 juin 20o9), Perpignan, Presses Universitaires de Perpignan, p. 229-239.

Maufras O., Alessandri P., Ratsimba A., 2011: «Aperçu de la gestion des eaux de pluie et des eaux domestiques à Nîmes et dans la plaine du Vistre entre les $\mathrm{X}^{\mathrm{e}}$ et XIV ${ }^{\mathrm{e}} \mathrm{s}$. », in, FABRE G., (DIR.), Temps de l'eau, sites et monuments entre Vidourle et Rhône, Bulletin de l'École Antique de Nîmes, 29, p. 45-84.

MAUfrAS O., RATSIMBA A., à paraître $\mathrm{a}:$ : La céramique médiévale du Mas de Vignoles XV à Nîmes (Gard) contribution à la caractérisation des $\mathrm{IX}^{\mathrm{e}}$ et $\mathrm{X}^{\mathrm{e}}$ siècles nîmois ", Archéologie du Midi Médiéval.

Maufras O., Mercier C., GARdeisen A., à paraître b : «La villa médiévale de Codols $\left(\mathrm{vII}^{\mathrm{e}}-\mathrm{XII}^{\mathrm{e}} \mathrm{s}\right.$.) : habitat et terroir ", in Pomaredes H., (Dir.), Barberan S., Maufras O., Sauvage L., La villa de Saint-André de Codols (Nîmes, Gard) : évolution de l'habitat et de l'espace rural nîmois de l'Antiquité au Moyen Âge (I ${ }^{\text {er }}$ s. - XII ${ }^{e}$ s. ap. J.-C.), Lattes, ADALR, (coll. Monographie d'Archéologie Méditerranéenne).

Mauné S., Bourgaut R., Paillet J.-L., Longepierre S. (COLlab.), MARCHAND G., (COLlab.), $2007:$ : Un moulin hydraulique du $\mathrm{II}^{\mathrm{e}}$ s. ap. J.-C. dans létablissement de l'Auribelle-Basse (Pézenas, Hérault) », in, BRUN J.-P., FICHES J.-L., (ED.), Énergie hydraulique et machines élévatrices d'eau dans l'Antiquité, Actes du Colloque International du Pont du Gard, Vers-Pont-du-Gard, 20-22 septembre 2006, Naples, Centre Jean Bérard (coll. du Centre Jean Bérard, 27), p. 115-148.

Mazière F., Martin S., Jorda C., Paillier C., Sendra B. 2012 : «La place du facteur naturel dans les dynamiques d'occupation protohistoriques. L'exemple de l'étang de Pézenas (Hérault, France), in, Ropiot V., PUig C., Maziere F., (DIR.), Les plaines littorales en Méditerranée Nord-occidentale, Regards croisés d'histoire, d'archéologie et de géographie de la protohistoire au Moyen âge, Table ronde de Capestang, 16 et 17 novembre 2007, Montagnac, Monique Mergoil, (coll. Archéologie du Paysage, 1), p. 13-32.

Pomarèdes H. (Dir.), Barberan S., Fabre L., Rigoir Y., 2005: La Quintarié (Clermont-l'Hérault, 34), Etablissement agricole et viticulture, atelier de céramiques paléochrétiennes (DS.P) $\left(I^{e r}-V I^{e}\right.$ s. ap. J.-C.) Montagnac, Monique Mergoil, (coll. Archéologie et histoire romaine, 14, Archéologie de l'A.75), 194 p.

Pomarèdes H. avec la collab. de Compan M Ginouvez O., Jung C., 2008 : « Viticulture et équipements de production dans la cité de Lodève durant le haut Empire : apport des découvertes récentes autour de Clermont-l'Hérault », Revue Archéologique de Narbonnaise, 41, p. 7-41.

Pomarèdes H., (Dir.), Barberan S., Maufras O. SAUVAGE L., à paraître: La villa de Saint-André de Codols (Nîmes, Gard) : évolution de l'habitat et de l'espace rural nîmois de l'Antiquité au Moyen Âge ( ${ }^{\text {er }}$ S. $-X I I^{e}$ s. ap. J.-C.), Lattes, ADALR, (coll. Monographie d'Archéologie Méditerranéenne).

POMARÈdES H., BREUIL J.-Y., 2006 : « Nîmes, réflexions sur l'origine et la romanisation du peuplement périurbain ", in, Rhythms and cycles of countryside romanization, Girona, Institut de Patrimoni Cultural de la Universitat de Girona, (coll. Estudis sobre el món rural d’època romana, 1), p. 115-130.

Pomarèdes H., Bel V., Breuil J.-Y., Celie M., Monteil M. SEJALON P., VIDAL L., à paraître : « Le paysage périurbain à Nîmes (Gard), de la Protohistoire au Haut-Empire, (vi ${ }^{\mathrm{e}}$ s. av. n. è. $-\mathrm{II}^{\mathrm{e}} \mathrm{s}$. de n. è.)», in Actes du colloque international, Le paysage périurbain pendant la protohistoire et l'Antiquité en Méditerranée occidentale, 6 - 8 mai 2009, Tarragone, Institut Català d'Arqueologia Clàssica.

Py M., 1990 : Culture, économie et société protohistoriques dans la région nîmoise, Rome, Ėcole Française de Rome, (coll. de l'Ècole Française de Rome, 131), p. 957.

SAUVAGE L., 1996: «Existe-t-il une ferme indigène dans le Midi de la France? », in, Bayard D., Collart J.-L. (DIR.), De la ferme indigène à la villa romaine, $L a$ romanisation des campagnes de la Gaule, Actes du Deuxième colloque de l'association AGER, Amiens (Somme), 23 au 25 septembre 1993, Revue Archéologique de Picardie, (coll. $n^{\circ}$ spécial, 11), p. 287-292.

Sejalon P., Bel V., Breuil J.-Y., Pomarèdes H., 2009 : « Définition et organisation des terroirs protohistoriques de Nîmes, Gard (de la fin du vi ${ }^{e}$ au I $^{\text {er }}$ s. av. J.-C.) », in, Bertrand I., Duval A., Gomez De Soto J., Maguer P., (DIR.), Habitats et paysages ruraux en Gaule et regards sur d'autres régions du monde celtique, Actes du XXXI colloque international de l'AFEAF, 17-20 mai 2007, Chauvigny (Vienne), Chauvigny, Association des Publications Chauvinoises, (coll. Mémoire 35, Société de recherches archéologiques de Chauvigny), tome II, p.153-18o. 